Research Article

\title{
Study the role of Urotensin II as a predictor for hepatorenal syndrome
}

\begin{abstract}
Bakground and objectives: Chronic liver disease and its complications is a common health problem worldwide. Hepatorenal syndrome (HRS type 1,2) is one of these serious complications with high mortality. The aim of this study was to evaluate the diagnostic role of urotensin II in patients with chronic liver diseases (both ascitic and non ascitic patients).

Patients and methods: Forty patients were selected from Gastroenterology, Hepatology and Infectious Diseases Department, Benha University Hospital, Egypt. Group (1) 20 patients with ascites ( 9 males and 11 females), their ages ranged from 35-65years with mean $50.95 \pm 9.84$. Group (2) 20 patients without ascites as a control group (8 males and 12 females) their ages ranged from 35-63 years with mean $49.25 \pm 9.66$, from the period of March 2011 to July 2011.
\end{abstract}

Results: There was no statistically significant difference as regard CBC parameters ( $\mathrm{p}>0.05$ ) between the ascitic group (1) and non ascitic group (2), except for platelet count, there was a statistically significant decrease between the 2 groups $(p<0.05)$. There was a statistically significant increase between the two groups as regard (ALT,T.B,DB and serum urea), $\mathrm{P}$ value $<0.05$, but no statistically significant difference as regards to total protein, serum albumin, alkaline phosphatase and serum creatinine ( $\mathrm{P}$ value $>0.05$ ). The Ultrasound findings of the kidney's were of statistically significant difference between the two groups as regard nephropathy ( 8 patients in ascitic group ${ }^{1}$ while one patient in non ascitic group ${ }^{2}$ ) ( $\mathrm{p}$ value $<0.05$ ). There was a statistically significant correlation between Urotensin II and blood urea level in group 2, but there was not with other variables. The cut-off value of Urotensin II was of sensitivity $66.7 \%$, specificity $64.5 \%$, PPV $35.3 \%$ and NPP $86.96 \%$ with Accuracy $59 \%$ and $p$ value $<0.42$ of no statistically significant difference.

Conclusion: Urotensin II was of statistically significant positive correlation with blood urea level in patients with ascites, that means the relevant clinical importance to use urotensin II in the early stages of liver disease before development of HRS. Also it can be used to diagnose subclinical hepatic encephalopathy patients , that is confirmed with other investigation.

Keywords: Chronic liver disease, Hepatorenal syndrome, Urotensin II
Volume 5 Issue 6 - 2016

\author{
Amal AL Mahdy,' Reda M EL Badawy, ${ }^{2}$ \\ Howyda M Kamal,' Eman R Abd EL Gawad' \\ 'Department of Clinical and chemical Pathology, Benha \\ University, Egypt \\ ${ }^{2}$ Department of Gastroenterology, Hepatology and Infectious \\ Diseases, Benha University, Egypt
}

Correspondence: Reda M EL-Badawy, Department of Gastroenterology, Hepatology and Infectious Diseases, Benha University, Egypt, Email dr_reda_b@yahoo.com

Received: July 12, 2016 | Published: November 29, 2016

\section{Introduction}

Hepatorenal syndrome (HRS) is the development of renal failure in patients with advanced chronic liver disease, ${ }^{1}$ occasionally fulminant hepatitis, who have portal hypertension and ascites. Estimates indicate that at least $40 \%$ of patients with cirrhosis and ascites will develop hepatorenal syndrome (HRS) during the natural history of their disease. ${ }^{2}$

In HRS, the histological appearance of the kidneys is normal, and the kidneys often resume normal function following liver transplantation. This makes HRS a unique pathophysiological disorder that provides possibilities for studying the interplay between vasoconstrictor and vasodilator systems on the renal circulation. ${ }^{3}$

Although a similar syndrome may occur in acute liver failure, HRS is usually described in the context of chronic liver disease. Despite some encouraging studies of new pharmacological therapies, the development of HRS in people with cirrhosis portends a dismal prognosis because renal failure is usually irreversible unless liver transplantation is performed. ${ }^{4}$

In the early phases of portal hypertension, renal perfusion is maintained within normal or near-normal limits as the vasodilatory systems antagonize the renal effects of the vasoconstrictor systems. However, as liver disease progresses in severity, a critical level of vascular underfilling is achieved. Renal vasodilatory systems are unable to counteract the maximal activation of the endogenous vasoconstrictors and/or intrarenal vasoconstrictors, which leads to uncontrolled renal vasoconstriction. ${ }^{5}$

The alternative theory proposes that renal vasoconstriction in HRS is unrelated to systemic hemodynamics but is due to either a deficiency in the synthesis of a vasodilatory factor or a hepatorenal reflex that leads to renal vasoconstriction. Evidence points to the vasodilatation theory as a more tangible explanation for the development of HRS. Urotensin II (U II) is a somatostatin-like cyclic peptide, its vascular tone both species specific and diseases specific. ${ }^{6}$ Urotensin II interfere with sympathetic and nitric oxide (NO) system. ${ }^{7}$

Direct evidence for the pathological role of U II in chronic liver disease has been found. In patients with chronic liver disease, serum $U$ II is elevated compared with controls. In addition, U II levels correlate with the severity of disease and with the extent of portal hypertension. Finally, the baseline of U II levels can even carry a predictive value for determining survival or future portal complications. ${ }^{8,9}$

So the aim of this study was to evaluate the level and the role of Urotensin II in grades of liver diseases (ascitic group and non ascitic group) and its use as predictor to diagnose patients with early hepatorenal syndrome. 


\section{Patients and methods}

Forty patients with chronic liver diseases selected from Gastroenterology, Hepatology and Infectious diseases Department, Benha University Hospital, from the period of March 2011 to July 2011. The patients were divided into 2 groups. Group (1) 20 patients, with ascites ( 9 males, 11 females) their age ranged from 35-65 years old with mean 50.95 9.84 . Group (2) 20 patients, without ascites (8 males, 12 females) their age ranged from35-63 years old with mean $49.25 \pm 9.66$ (as a control group). All the patients undergone history taking, full clinical examinations for the clinical signs of chronic liver disease and any manifestations of renal disorder, that non specific in these patients. A written consents were taken from the patients, according to the ethical committee of the collage, Benha University Hospital.

\section{Exclusion criteria}

i. DM. Hypertensive patients and severe heart failure.

ii. Patients in bleeding at the time of taking blood sample or 3 days previously.

iii. Patients on diuretics for previous 3 days.

\section{Inclusion criteria}

Patients with liver cirrhosis with and without ascites.

Abdominal ultrasound: For evaluation of liver (size, echogencity, manifestations of portal hypertension (PH), focal lesion) and confirm the presence of ascites. Evaluation of splenic size to prove $\mathrm{PH}$, by the presence of hilar collaterals and widen the diameter of splenic vein. Kidney's evaluation for size and grades of nephropathy and the presence of stone.

\section{Method}

Nine $\mathrm{ml}$ blood samples were taken from each patient, and were divided into four tubes; one tube containing $1 \mathrm{ml}$ blood with EDTA was used for complete blood count (CBC) using Sysmex 21-X. The second tube containing $4 \mathrm{ml}$ blood (without anticoagulant) was used to separate serum (after centrifugation) for biochemical analysis liver and kidney function tests using Bio Systems-15, and the rest of this serum was stored at $-20{ }^{\circ} \mathrm{C}$ till the time of assay of Urotensin II by ELISA. The third tube is plastic graduated tube, containing 0.2 $\mathrm{ml} \mathrm{Na}$ citrate and completed to $2 \mathrm{ml}$ with blood (with ratio 1:9) for measuring PT and APTT using Option-4 Coagulomater. The fourth tube was containing $0.5 \mathrm{ml} \mathrm{Na}$ citrate and completed to $2 \mathrm{ml}$ with blood (with ratio 1:4) for measuring ESR using Westergreen method.

Urotensin II level was measured by using immune diagnostic ELISA Kits (Cat. No. K 1013 - 110429) according to the manufacturer's instructions. The absorbance was read on microplate reader at reading wave length $450 \mathrm{~nm}$ length.

\section{Statistical methods}

The collected data were tabulated and analyzed using SPSS version 16 soft ware. Categorical data were presented as number and percentages while quantitative data were expressed as mean and standard deviation. Urotensin II values were not normally distributed so; it was presented as median and range using Mann Whitney test and Spearman's correlation coefficient for analysis. Chi square test (X2) and student " $t$ " test were used as tests of significance for parametric data. ROC curve was used to detect a cutoff value of urotensin II with optimum sensitivity and specificity. The accepted level of significance in this work was stated at $0.05(\mathrm{P}<0.05)$ was considered significant.

\section{Results}

Table 1 shows a statistical significant difference between the groups as regards to the mean number of platelets being decreased in ascitic group (1) than non ascitic group (2) (P value $<0.019$ ), but there was no statistical significance for other $\mathrm{CBC}$ parameters, $\mathrm{PT}$ and PTT, ( $\mathrm{P}$ value $>0.05$ ). Also, there was statistical significant difference between the 2 groups as regard ALT,TB, DB and urea, ( $\mathrm{P}$ value $<0$. 0.5 ), and nephropathy being increased in ascitic group (1) than non ascitic group (2) (P value $<0.05)$ (Table 2\&3).

Table I CBC among the studied groups

\begin{tabular}{|c|c|c|c|c|c|c|c|c|c|}
\hline \multirow{2}{*}{$\begin{array}{l}\text { Group } \\
\text { Parameter }\end{array}$} & \multicolumn{3}{|c|}{$\begin{array}{l}\text { Group I (Ascitic) } \\
(\mathrm{N}=\mathbf{2 0})\end{array}$} & \multicolumn{3}{|c|}{$\begin{array}{l}\text { Group II (Non Ascitic) } \\
(\mathrm{N}=\mathbf{2 0})\end{array}$} & \multirow[t]{2}{*}{ St."t" } & \multirow{2}{*}{\multicolumn{2}{|c|}{$\mathbf{P}$}} \\
\hline & Range & $\pm \mathrm{SD}$ & Mean & Range & $\pm \mathrm{SD}$ & Mean & & & \\
\hline WBCs (x109/L) & $1.9-18.8$ & 4.72 & 6.66 & $2.3-15$ & 4.2 & 7.63 & 0.69 & & 0.5 \\
\hline RBCs $\left(\times 10^{12} / L\right)$ & $2-4.73$ & 0.66 & 3.17 & $2.3-4.87$ & 0.64 & 3.34 & 0.83 & & 0.41 \\
\hline $\mathrm{Hb}(\mathrm{g} / \mathrm{dl})$ & $4.13-12.7$ & 2.17 & 9.43 & $5.1-14.7$ & 2.3 & 9.72 & 0.39 & & 0.69 \\
\hline HCT (\%) & $2 \mathrm{I}-38.4$ & 4.93 & 29.75 & $18.6-43.8$ & 5.93 & 29.52 & 0.13 & & 0.9 \\
\hline MCV (FL) & $74.6-106$ & 8.21 & 93.38 & $66-100$ & 7.83 & 88.53 & 1.9 & & 0.063 \\
\hline $\mathrm{MCH}(\mathrm{pg})$ & $21.3-35$ & 3.68 & 30.2 & $20-34.6$ & 3.5 & 28.64 & 1.4 & & 0.18 \\
\hline $\mathrm{MCHC}(\mathrm{g} / \mathrm{dl})$ & $25.1-35$ & 2.08 & 32.25 & $23-36.6$ & 3.65 & 29.34 & 0.82 & & 0.42 \\
\hline PLT (xI03/cmm) & $28-219$ & 58.48 & 92.7 & $25-444$ & 115.06 & 163.25 & 2.44 & & $0.019 *$ \\
\hline $\operatorname{ESR}(\mathrm{mm}$ in I h) & $20-140$ & 31.43 & 50.6 & $25-150$ & 29.84 & 46.75 & 0.39 & & 0.69 \\
\hline Group & \multicolumn{3}{|c|}{ Group I (Ascitic) } & \multicolumn{3}{|c|}{ Group II (Non Ascitic) } & St. "t" & & P \\
\hline Parameter & Range & $\pm S D$ & Mean & Range & & $\pm S D$ & Mean & & \\
\hline PT (sec.) & $10.6-47.7$ & 8.71 & 20.99 & $11.5-4.2$ & & 6.96 & 17.08 & 1.51 & 0.14 \\
\hline INR & $0.78-7.16$ & 1.51 & 2.23 & $0.88-5.78$ & & I.I & 1.67 & 1.3 & 0.2 \\
\hline A PTT (sec.) & $22.1-73$ & 13.38 & 39.18 & 11.2-72 & & 12.59 & 34.75 & 1.01 & 0.32 \\
\hline
\end{tabular}


Table 2 Liver and Kidney profile among the studied groups

\begin{tabular}{|c|c|c|c|c|c|c|c|c|}
\hline \multirow{2}{*}{$\begin{array}{l}\text { Group } \\
\text { Parameter }\end{array}$} & \multicolumn{3}{|c|}{$\begin{array}{l}\text { Group I (ascitic) } \\
(\mathbf{N}=\mathbf{2 0})\end{array}$} & \multicolumn{3}{|c|}{$\begin{array}{l}\text { Group II (non ascitic) } \\
(\mathrm{N}=20)\end{array}$} & \multirow[t]{2}{*}{ St. "t" } & \multirow[t]{2}{*}{$\mathbf{P}$} \\
\hline & Range & $\pm S D$ & Mean & Range & $\pm S D$ & Mean & & \\
\hline S.ALT (U/L) & $35-180$ & 38.75 & 77.65 & $21-153$ & 30.02 & 50.05 & 2.5 & $0.016 *$ \\
\hline S.AST (U/L) & $20-123$ & 27.22 & 58.55 & $14-120$ & 24.25 & 43.3 & 1.87 & 0.69 \\
\hline S.T bilirubin (mg/dl) & $0.8-5.5$ & 1.09 & 2.1 & $0.5-2.3$ & 0.44 & 1.15 & 3.6 & $0.001 * *$ \\
\hline S.D bilirubin (mg/dl) & $0.1-2.8$ & 0.72 & 1.04 & $0.1-I .1$ & 0.33 & 0.46 & 3.3 & $0.002 *$ \\
\hline S.T. protein $(\mathrm{g} / \mathrm{dl})$ & $\mathrm{I}-6.8$ & 1.59 & 4.77 & $2.2-7.0$ & 1.14 & 5.54 & 1.76 & 0.086 \\
\hline S.Albumin (g/dl) & $0.3-3.5$ & 0.81 & 2.27 & $1.7-3.9$ & 0.55 & 2.9 & 2.88 & 0.06 \\
\hline S.ALP (U/L) & $79-200$ & 39.15 & 120.95 & $70-200$ & 43.98 & 122.5 & 0.12 & 0.91 \\
\hline S. Urea (mg/dl) & $32-170$ & 31.4 & 56.6 & $30-53$ & 7.56 & 39.85 & 2.3 & $0.026 *$ \\
\hline S. Creatinine $(\mathrm{mg} / \mathrm{dl})$ & $0.6-5.9$ & 1.17 & 1.5 & $0.7-1.7$ & 0.31 & 1.08 & 1.6 & 0.12 \\
\hline
\end{tabular}

Table 3 Ultrasonic findings of kidney among the studied groups

\begin{tabular}{|c|c|c|c|c|c|c|}
\hline \multirow{2}{*}{ Kidney (US) } & & \multicolumn{2}{|l|}{ Group } & \multirow{2}{*}{-Total } & \multirow{2}{*}{$\mathbf{X}^{2}$} & \multirow{2}{*}{$\mathbf{P}$} \\
\hline & & Group I & Group II & & & \\
\hline \multirow[t]{2}{*}{ Normal } & Number of cases & 12 & 16 & 28 & \multirow{10}{*}{9.02} & \multirow{10}{*}{$0.029 *$} \\
\hline & $\%$ within group & $60.00 \%$ & $80.00 \%$ & $70.00 \%$ & & \\
\hline \multirow[t]{2}{*}{ Nephropathy } & Number of cases & 8 & I & 9 & & \\
\hline & $\%$ within group & $40.00 \%$ & $5.00 \%$ & $22.50 \%$ & & \\
\hline \multirow[t]{2}{*}{ Polycystic } & Number of cases & 0 & 1 & I & & \\
\hline & $\%$ within group & $0 \%$ & $5.00 \%$ & $2.50 \%$ & & \\
\hline \multirow[t]{2}{*}{ Stones } & Number of cases & 0 & 2 & 2 & & \\
\hline & $\%$ within group & $0 \%$ & $10.00 \%$ & $5.00 \%$ & & \\
\hline \multirow[t]{2}{*}{ Total } & Number of cases & 20 & 20 & 40 & & \\
\hline & $\%$ within group & $100.00 \%$ & $100.00 \%$ & $100.00 \%$ & & \\
\hline
\end{tabular}

In Table 4 the correlation between the Urotensin II level with different variables, shows that there was a statistical significant positive correlation between Urotensin II and blood urea level ( P value 0.016 ). While Table 5 shows non significant correlation between urotensin level and the studied groups $(\mathrm{P}>0.05)$. Table 6 shows statistically non-significant difference in urotensin II level between; Cirrhotic patients and controls; Cirrhotic with ascites and cirrhotic without ascites; Cirrhotic with hepatorenal syndrome and cirrhotic without hepatorenal syndrome; HCV abs +vet patients and HCV abs -ve patients and HBV Ag + ve patients and HBV Ag -ve patients.

Table 4 Spearman's correlation between urotensin II level and some studied variables

\begin{tabular}{lllll}
\hline $\begin{array}{l}\text { Correlation between } \\
\text { urotensin and }\end{array}$ & $\begin{array}{l}\text { Group I (Ascitic) } \\
\mathbf{( N = 2 0 )}\end{array}$ & $\begin{array}{l}\text { Group II (Non } \\
\text { ascitic) } \mathbf{( N = 2 0 )}\end{array}$ \\
Age (year) & $\mathbf{R}$ & $\mathbf{P}$ & $\mathbf{r}$ & $\mathbf{P}$ \\
ALT(U/L) & 0.439 & 0.053 & 0.12 & 0.61 \\
AST(U/L) & -0.07 & 0.77 & -0.166 & 0.48 \\
Alk. Phos. (U/L) & -0.009 & 0.97 & -0.29 & 0.22 \\
Urea (mg/l) & 0.352 & 0.13 & 0.147 & 0.54 \\
Creatinine(mg/l) & 0.212 & 0.37 & 0.532 & $0.0 .16^{*}$ \\
Esophageal cords & 0.21 & 0.38 & 0.246 & 0.3 \\
Esophageal grade & -0.08 & 0.74 & 0.078 & 0.74 \\
Degree of ascites & 0.255 & 0.28 & 0.017 & 0.94 \\
PT (sec.) & 0.2 & 0.39 & - & - \\
INR & -0.38 & 0.12 & 0.237 & 0.32 \\
PTT (sec.) & -0.44 & 0.069 & 0.23 & 0.34 \\
\hline
\end{tabular}

Table 5 Urotensin level among the studied groups

\begin{tabular}{llllll}
\hline \multirow{2}{*}{ The Studied Variable } & \multicolumn{3}{c}{ Urotensin Level } & Krauskal Wallis & P \\
\cline { 2 - 6 } & $\mathbf{N}$ & Median & Range & Test & \\
\hline Cirrhotic with ascites & 20 & 25645 & $5114-104490$ & & \multirow{2}{*}{0.46} \\
Cirrhotic without ascites & 20 & 22365 & $5227-71020$ & 1.55 & \\
Control Group & 10 & 22167 & $5215-71000$ & & \\
\hline
\end{tabular}


Table 7 shows the cut off value of urotensin II with sensitivity, specificity, PPV, NPV, Accuracy and $95 \%$ CI of AUC with no statistical significant ( $\mathrm{P}$ value 0.42 ). Figure 1 shows positive correlation between the Urotensin II and blood urea (P value, 0.016). Figure 2 ROC curve shows that Urotensin II level was non significant diagnostic test for hepatorenal syndrome (AUC was $0.59 \& \mathrm{P}$ value was $>0.05$ ).

Table 6 Urotensin level according to some studied variables

\begin{tabular}{|c|c|c|c|c|c|}
\hline \multirow{2}{*}{ The Studied Variable } & \multicolumn{3}{|c|}{ Urotensin level (pg/ml) } & \multirow{2}{*}{ MW Test } & \multirow{2}{*}{$\mathbf{P}$} \\
\hline & $\mathbf{N}$ & Median & Range & & \\
\hline Cirrhotic & 40 & 23420 & $5114-104490$ & & \\
\hline Cirrhotic with ascites & 20 & 25645 & $5114-104490$ & & \\
\hline Cirrhotic without ascites & 20 & 22365 & $5227-71020$ & 156 & 0.23 \\
\hline Cirrhotic with hepatorenal S. & 9 & 29480 & $9257-91710$ & & \\
\hline Cirrhotic without hepatorenal S. & 31 & 22720 & $5114-104490$ & II4.5 & 0.42 \\
\hline HCV abs +ve & 24 & 26425 & $5114-91410$ & & \\
\hline HCV abs -ve & 16 & 20610 & $7384-91410$ & 155 & 0.31 \\
\hline HBVs Ag +ve & 8 & 21125 & 7384-91410 & & \\
\hline $\mathrm{HBVs} \mathrm{Ag}-\mathrm{ve}$ & 32 & 23330 & $5114-104490$ & 118 & 0.74 \\
\hline
\end{tabular}

Table 7 The cut off value of urotensin II with sensitivity, specificity, PPV, NPV,Accuracy and $95 \% \mathrm{Cl}$ of AUC

\begin{tabular}{|c|c|c|c|c|c|c|c|c|}
\hline Urotensin II & Sensitivity & Specificity & PPV & NPV & Accuracy & AUC & $95 \% \mathrm{Cl}$ of AUC & $\mathbf{p}$ \\
\hline Cut off value: 24725 & $66.70 \%$ & $64.50 \%$ & $35.30 \%$ & $86.96 \%$ & $59 \%$ & 0.59 & $0.37-0.81$ & 0.42 \\
\hline
\end{tabular}

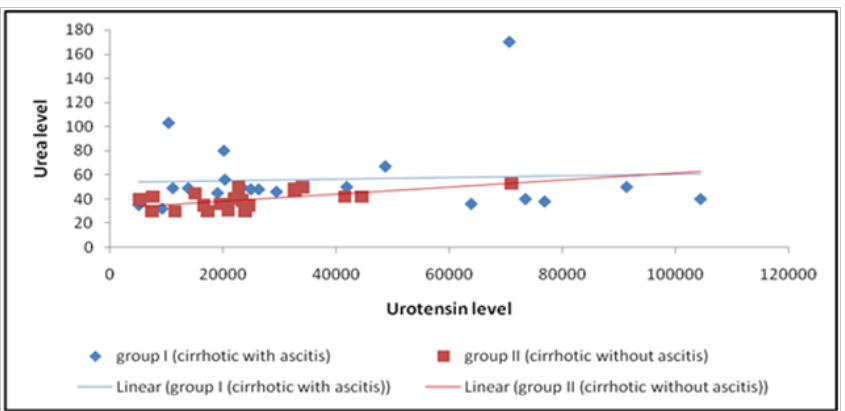

Figure I Correlation between urotensin level $(\mathrm{pg} / \mathrm{ml})$ and urea level $(\mathrm{mg} / \mathrm{dl})$ in the two studied groups.

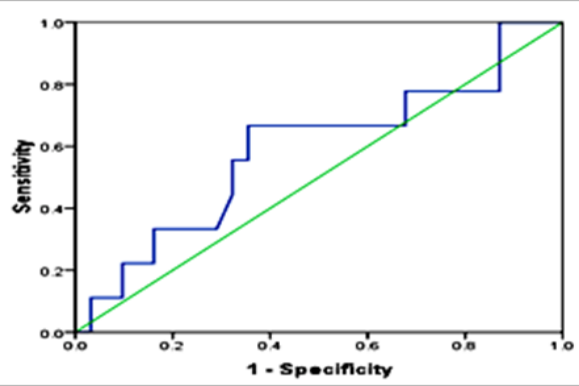

Figure 2 ROC curve for accuracy and predictivity of urotensin in diagnosis of hepatorenal syndrome.

\section{Discussion}

HRS is common, with a reported incidence of $10 \%$ among hospitalized patients with cirrhosis and ascitesm. ${ }^{10}$ In decompensated cirrhotics, the probability of developing HRS with ascites ranges between $8-20 \%$ per year and increases to $40 \%$ at 5 years.

The diagnosis of HRS is one of exclusion and depends mainly on serum creatinine level, as no specific tests establish the diagnosis of HRS. Although serum creatinine level is a poor marker of renal function in patients with cirrhosis, no other validated and reliable noninvasive markers exist for monitoring renal function in these patients. ${ }^{11}$ Diagnosis of HRS is based on the presence of a reduced GFR in the absence of other causes of renal failure in patients with chronic liver disease according to the criteria proposed by the International Ascites Club in $1996 . .^{2}$ So the aim of this study was to evaluate the level and the role of urotensin II in different grades of chronic liver diseases(patients with ascites and without ascites), due to the difficulty in assessment of GFR in critically ill patients. The limitations of serum creatinine as a measure of glomerular filtration rate (GFR) have lead to an extensive search for a more sensitive laboratory marker of impaired renal function. ${ }^{13}$ In the present study, 2 groups were selected as having HRS matched as regard age and sex, 20 patients in each group (ascitic and non ascitic).

In Table 1, there was no statistical significant difference as regard $\mathrm{CBC}$ and Coagulation profile except the platelets count, where there was a statistical significant difference between the two groups with $\mathrm{P}$ value 0.019 . The explanation for that is agree with that known in the literatures and the normal sequelae of progression of the diseases and the use platelets with AST, AST to platelet ratio index (APRI) as noninvasive marker to diagnose liver cirrhosis. Also the maintenance of the platelets count to normal value in the early stage of the diseases and tendency to drop after the disease progress, this is due to an increased intrasplenic platelet breakdown with variable roles of decreased platelet production and splenic pooling appear to be the most important determinants. Regarding the functional change, there is a decreased aggregability attributable to defective (transmembrane and intracellular) signaling, a storage pool defect and an up regulation of the inhibitory pathways..$^{14}$

As regard the result of liver and kidney function tests between the 2 groups ,there was a statistical significant difference as regard ALT, Total bilirubin, direct bilirubin as well as blood urea level, $\mathrm{P}$ value $<0.05$, while that of albumin, total protein, alkaline phosphates and serum creatinine was of no statistical significant difference, $\mathrm{P}$ value $>0.05$, Table 2 . That is agree with Herget-Rosenthal et al..$^{15} \&$ Nejat et al. ${ }^{13}$ who reported in their studies, that serum creatinine level is not sensitive or specific to diagnose reduced GFR compared to serum Cystatin C (a protein synthesized from all nucleated cells excreted 
unchanged from the kidney). The explanation in our study most probably is that the new and virgin ascites and also the patients in early stage of liver disease had normal creatinine level. Only a minority of patients with cirrhosis and elevated serum creatinine fulfills the criteria of hepatorenal syndrome. ${ }^{16}$ So the using of Urotensin II that act as vascular mediator according the organ situations seems to be accurate than substances excreted by the kidney. It is crucial to distinguish between patients with hepatorenal syndrome and those patients with other causes of renal Impairment.

In the present study the ultrasound findings of the kidney was of statistical significant, P value 0.029 , Table 3 . Picture of nephropathy was evident in group (1) with ascitis compared with non ascitic group (group 2) and that was known in the literature done byPlatt et al. ${ }^{17}$ who found that the grades of nephropathy associated with increase severity of chronic liver diseases. The correlation between Urotensin II and other variables was positively correlated with the serum urea level in group 2 (non - ascitic), P value 0.016 ,but there was no correlation with other parameters in both groups Table 4, Figure 1. The cut-off value for Urotensin II was of sensitivity $66.7 \%$, specificity $64.5 \%$ by ROC curve Figure 2 with PPV $35.3 \%$ and NPV 86.96\%. Accuracy was $59 \%$, area under the curve was (AUC 0.59), 95\% CI of AUC was $0.37-0.81$ (P value, 0.42) (Table 5 \& Figure 2). To our knowledge there are no studies in literature that could be compared to the results of the present work.

\section{Conclusion}

Urotensin II was correlated positively with plasma urea level in patients without ascites and with ALT, TB and DB in patients with ascites, that is mean, it negatively correlated with severity of liver disease especially in mild and moderate cases. So, we can use UT II as early predicator of hepatorenal syndrome in ascetic patients to avoid the high mortality that resolve by liver and kidney transplantation in some cases.

\section{Recommendations}

This vasoactive mediator(UT II) can be added in the work up of investigations for patients with chronic liver diseases especially without ascites and that will be of value especially in patients pass to encephalopathy (combined with high blood urea level). Also, further studies on a large number of patients to confirm these results.

\section{References}

1. Betrosian AP, Agarwal B, Douzinas EE. Acute renal failure in liver diseases. World J Gastroenterol. 2007;14:13(42):5552-5559.

2. Ben Chaabane N, Melki W, Hellara O, et al. Hepatorenal syndrome. Tunis Med. 2011;89(12):885-890.
3. Lau C, Marbin P and Bunnapradist S. Management of renal dysfunction in patients receiving a liver transplant. Clin liver Dis. 2011;15(4):807 -820 .

4. Wing F, Raina N, Richardison R. Molecular adsorbant recirculating system is ineffective in the management of type 1 hepatorenal syndrome in cirrhotic patients with ascites whom have failed vasoconstrictive therapy. Gut. 2009;59(3):381-386.

5. Moreau R, Lebrec D. Diagnosis and treatment of hepatorenal syndrome in patients with cirrhosis. Best Practice Res Clin Gastroenterol. 2007;2(1):111-123.

6. Ross B, McKendy K, Giaid A. "Role of urotensin II in health and disease". Am J Physiol Regul Integr Comp Physiol. 2010;298(5):1156-1172.

7. Zoccali C, Mallamaci F, Benedetto FA, et al. Urotensin II and cardiomyopathy in end-stage renal disease. Hypertension. 2008;51(2):326-333.

8. Kemp W, Krum H, Colman J, et al. Urotensin II:a novel vasoactive mediator linked to chronic liver disease and portal hypertension. Liver Int. 2007;27(9):1232-1239.

9. Kemp W, Roberts S, Krum H. Increased circulating urotensin II in cirrhosis:potential implications in liver disease. Peptides. 2008;29(5):868-872.

10. Carvalho GC, Regis Cde A, Kalil JR, et al. Causes of renal failure in patients with decompensated cirrhosis its impact in hospitalized patients. Ann Hepatol. 2012;14(1):90-95.

11. Shepke M. Hepatorenal syndrome - Current diagnosis \& therapeutic concept. Nephro Dial Transplant. 2007;22 $2^{\text {Suppl8}: v i i i 2-v i i i 4 . ~}$

12. Arroyo V, Ginès P, Gerbes AL, et al. Definition and diagnostic criteria of refractory ascites and hepatorenal syndrome in cirrhosis. Hepatology. 1996;23(1):164-176.

13. Nejat M, Pickering J W, Walker RJ, et al. Rapid detection of acute kidney injury by plasma cystatin $\mathrm{C}$ in the intensive care unit Nephro. Dial Transplant. 2010;25(10):4283-3289.

14. Witters P, Freson K, Verslype C, et al. Review article:blood platelet number and function in chronicliver disease and cirrhosis. Aliment Pharmacol Ther. 2008;27(11):1017-1029.

15. Herget-Rosenthal S, Trabold S, Pietruck F, et al. Cystatin C :efficacy as screening test for reduced glomerular filtration rate. Am J Nephrol. 2000;20(2):97-102.

16. Ginès $\mathrm{P}$, Guevara $\mathrm{M}$, Arroyo V. Hepatorenal syndrome. Lancet. 2003;362(9398):1819-1827.

17. Platt J F, Ellis J H, Rubin JM. Renal duplex doppler ultrasonography:A noninvasive predictor of kidney dysfunction and hepatorenal failure in liver disease. Hepatology. 1994;20(2):362-369. 